\title{
Measurement of creatinine in human plasma using a functional porous polymer structure sensing motif
}

\author{
Sitansu Sekhar Nanda' \\ Seong Soo A An' \\ Dong Kee $\mathrm{Yi}^{2,3}$ \\ 'Department of Bionanotechnology, \\ Gachon Medical Research Institute, \\ Gachon University, Seongnam, \\ ${ }^{2}$ Department of Chemistry, \\ ${ }^{3}$ Department of Environmental \\ Engineering, Myongji University, \\ Yongin, South Korea
}

This article was published in the following Dove Press journal:

International Journal of Nanomedicine

25 August 2015

Number of times this article has been viewed
Abstract: In this study, a new method for detecting creatinine was developed. This novel sensor comprised of two ionic liquids, poly-lactic-co-glycolic acid (PLGA) and 1-butyl-3methylimidazolium (BMIM) chloride, in the presence of $2^{\prime}, 7^{\prime}$-dichlorofluorescein diacetate (DCFH-DA). PLGA and BMIM chloride formed a functional porous polymer structure (FPPS)like structure. Creatinine within the FPPS rapidly hydrolyzed and released $\mathrm{OH}^{-}$, which in turn converted DCFH-DA to DCFH, developing an intense green color or green fluorescence. The conversion of DCFH to $\mathrm{DCF}^{+}$resulted in swelling of FPPS and increased solubility. This $\mathrm{DCF}^{+}-$ based sensor could detect creatinine levels with detection limit of $5 \mu \mathrm{M}$ and also measure the creatinine in blood. This novel method could be used in diagnostic applications for monitoring individuals with renal dysfunction.

Keywords: PLGA, FPPS, creatinine, blood, diagnosis

\section{Introduction}

Creatinine is the end product of the metabolic pathway of creatinine catabolism. Creatinine produced in the body is continuously removed from the blood circulation by the kidneys in large volumes daily. ${ }^{1}$ The level of creatinine in human blood and urine could be used as an indirect indicator of renal, muscular, and thyroid functions. Measuring creatinine levels would be also important for the biomedical diagnosis of acute myocardial infarction and in hemodialysis therapy. The normal level of creatinine in the blood of a healthy individual is $40-150 \mu \mathrm{M}$, but it can exceed $1,000 \mu \mathrm{M}$ in certain extreme circumstances. Patients with severe renal deficiency could have creatinine levels greater than $500 \mu \mathrm{M}$ and may eventually require dialysis or kidney replacement. At the other extreme, the creatinine level less than $40 \mu \mathrm{M}$ could be indicative of decreased muscle mass. ${ }^{2}$ Hence, regular measurement of creatinine in bodily fluids and rapid availability of results could greatly benefit critically ill patients with acute kidney injury, with timely administration of treatment to peritoneal dialysis patients for improving their quality of life. ., $^{3}$

Presently, colorimetric methods of testing creatinine are the more common techniques for measuring creatinine. These methods are based on using either Jaffe's reaction ${ }^{5}$ or the enzymatic colorimetric method. ${ }^{6}$ However, numerous metabolites and drugs in the sample can also interfere with these methods. ${ }^{7}$ Also, a long waiting period for the results can be a problem for the efficient treatments. ${ }^{8}$ Moreover, methods, such as Jaffe's reaction, are not selective for creatinine and can detect a wide range of biomolecules, such as sugar, urea, uric acid, pyruvate, and dopamine. ${ }^{6}$ Other available methods, such as ion-sensitive field effect transistor creatinine sensors ${ }^{9-13}$ 
and monoenzyme and trienzyme cascade biosensors, ${ }^{14-21}$ also have limitations in terms of their creatinine-sensing properties, such as low sensitivity and limited reproducibility.

In this study, functional porous polymer structure (FPPS) with 1-butyl-3-methylimidazolium (BMIM) chloride and poly-lactic-co-glycolic acid (PLGA) was prepared in the presence of $2^{\prime}, 7^{\prime}$-dichlorofluorescein diacetate (DCFH-DA) for sensing creatinine. PLGA and BMIM chloride formed the cross-linked FPPS by forming ester bonds. Next, the FPPS converts DCFH-DA to DCFH. ${ }^{22}$ BMIM revealed many interesting properties such as the fact that BMIM can exist as an ionic liquid at room temperature, which could in turn supports organic synthesis and catalytic reactions. ${ }^{23-25}$ Here, BMIM could help the catalytic activity of a reaction by producing $\mathrm{OH}^{-}$upon hydrolysis of creatinine. This $\mathrm{OH}^{-}$ could convert $\mathrm{DCFH}$ to $\mathrm{DCF}^{+}$, which produced a green color in the final step. A series of experiments was performed to measure creatinine in buffer and was then applied to blood plasma samples from patients with diabetes and Alzheimer's disease.

\section{Materials and methods Materials and characterization}

BMIM chloride, dichloromethane (DCM), PLGA, DCFH-DA, creatinine, urea, glucose, lactose, and sodium phosphate buffer were purchased from Sigma-Aldrich Inc. (St Louis, MO, USA). Diabetes patient blood sample and normal blood sample were obtained from Gachon Gil Hospital, South Korea. Alzheimer's patient blood sample was obtained from Seoul National University Bundang Hospital, South Korea. A field emission scanning electron microscope JSM 7500F (JEOL, Tokyo, Japan) was used to assess the morphology of FPPS. The photoluminescence measurements were carried out on Varian Spectrofluorometer at $350 \mathrm{~nm}$ excitation wavelength. In Varian Spectrofluorometer, a $1 \times 1 \mathrm{~cm}$ cuvette and a band pass of $10 \mathrm{~nm}$ for both excitation and emission were used. Microplate reader (Perkin Elmer, Waltham, MA, USA) was used to count the fluorescence intensity.

\section{Preparation of FPPS}

PLGA slurry was prepared by dissolving $100 \mathrm{mg}$ PLGA (50:50) in $10 \mathrm{~mL}$ of DCM, and then homogenized using a magnetic stirrer at $50^{\circ} \mathrm{C}$ for 12 hours. For preparing microporous-structured PLGA, BMIM chloride was chosen as the counter-phase, and $200 \mathrm{mg}$ was added to the PLGA slurry. The PLGA-BMIM chloride mixture was fabricated into FPPS with macrochannels, using a robotic dispensing method. In this method, the PLGA-BMIM mixture solution was filled into a syringe and placed in an ethanol bath.

\section{Detection of creatinine}

To check the viability of the testing method, $100 \mu \mathrm{L}$ of $100 \mu \mathrm{M}$ DCFH-DA was added to FPPS in the presence of various concentrations of creatinine $(25,50,100,150,200$, and $250 \mu \mathrm{M})$. The reaction mixture was incubated in the dark for 2 hours. Green fluorescence that developed was measured at the peak of emission wavelength at $530 \mathrm{~nm}$, with excitation at $350 \mathrm{~nm}$. The green fluorescence is also visible under normal white light.

\section{Preparation of blood sample}

Blood plasma samples (five) and normal blood samples (five) from diabetic patients and normal healthy persons were collected, with informed consent, from Gachon Gil Hospital, South Korea. Alzheimer patient blood samples (five) were collected, with informed consent, from Seoul National University Bundang Hospital, South Korea. The blood was collected in ethylenediaminetetraacetic acid (EDTA) or heparin vacutainer tubes and subjected to centrifugal separation for 30 minutes at $850 \mathrm{rpm}$. Informed consents were obtained prior to the blood sampling, and the protocol was approved by the Institutional Review Board of the Gachon University Gil Hospital and Seoul National University Bundang Hospital. After centrifugal separation, $1 \mathrm{~mL}$ of the separated plasma was dispensed into a $1.5 \mathrm{~mL}$ polypropylene tube (not mixed with blood cells) and stored at $-70^{\circ} \mathrm{C}$ until use. Prior to determination of creatinine in blood, the samples were centrifuged at 10,000 rpm for 30 minutes. Then, $20 \mu \mathrm{L}$ of supernatant was diluted with $80 \mu \mathrm{L}$ of $0.5 \mathrm{mM}$ sodium phosphate buffer solution.

\section{Detection of creatinine in blood}

For measuring creatinine in blood plasma, $5 \mathrm{mg}$ of FPPS was added to a diluted blood sample. Next, $100 \mu \mathrm{L}$ of $100 \mu \mathrm{M}$ DCFH-DA was added to the blood plasma sample, and the mixture was kept in the dark for 2 hours. After the incubation period, the solution showed green fluorescence. The final product from FPPS, DCFH-DA, and creatinine from blood plasma was measured, with excitation and emission wavelengths at $350,530 \mathrm{~nm}$, respectively.

\section{Results and discussion Characterization of PLGA FPPS and measurement of creatinine}

Scanning electron microscopy images of slurry mixture of DCM and PLGA revealed the absence of pores in the 

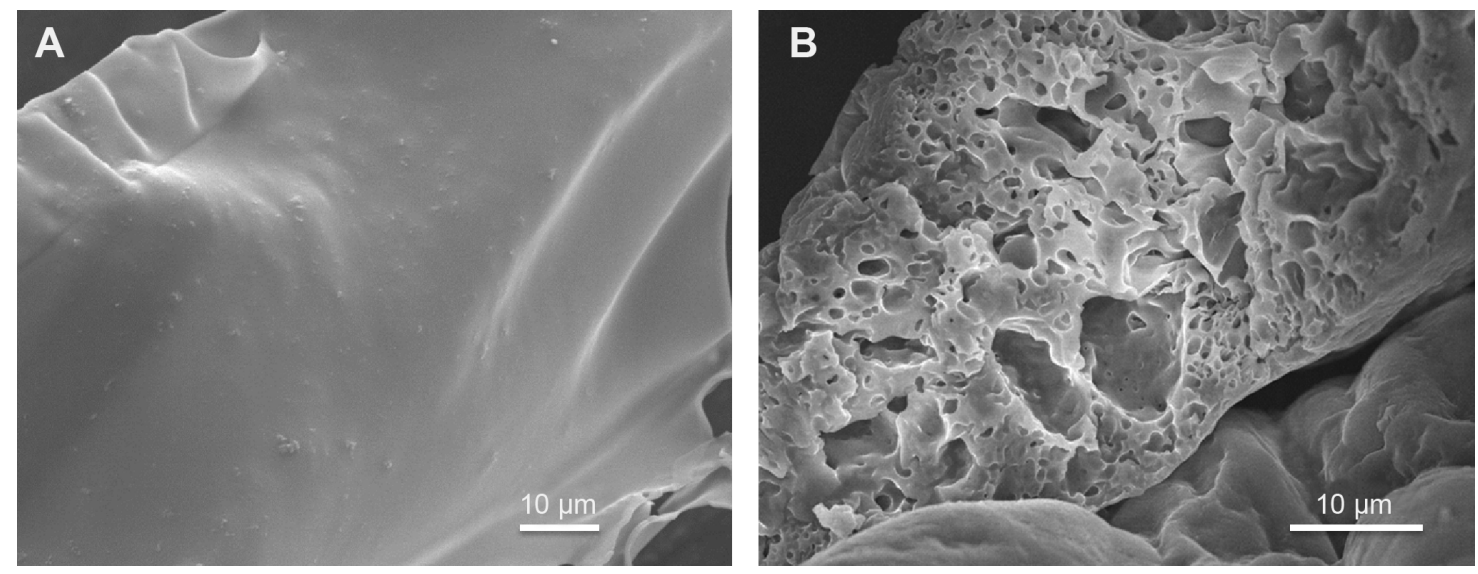

Figure I PLGA with functional porous polymer structure.

Note: (A) The SEM image of PLGA (control) and (B) pores in PLGA completely cross-linked with BMIM chloride.

Abbreviations: BMIM, I-butyl-3-methylimidazolium; PLGA, poly-lactic-co-glycolic acid; SEM, scanning electron microscopy.

mixture in Figure 1A. On the other hand, Figure 1B showed that addition of BMIM chloride resulted in the cross-linked structure of BMIM with PLGA and the creation of pores, which were mainly due to the formation of ester linkages. The mechanism of pore formation is outlined in Figure 2. First, the ester linkages converted DCFH-DA to DCFH. Simultaneously, as creatinine entered into the pore, it would go through hydrolysis to produce $\mathrm{OH}^{-}$. Next, $\mathrm{OH}^{-}$ion could convert $\mathrm{DCFH}$ to $\mathrm{DCF}^{+}$. Finally, as the concentration of $\mathrm{OH}^{-}$increased, the $\mathrm{DCF}^{+}$concentrations also increased and produces green color and fluorescence at $530 \mathrm{~nm}$. The average size of the pore is shown in Figure 3, with $X$ - and $Y$-axis of 18.214 and $17.946 \mu \mathrm{m}$, respectively. The estimated diameter of the pore was $25.570 \mu \mathrm{m}$. The surface chemistry of the pore and catalytic activity of the ionic liquid plays a vital role in the effectiveness of the creatinine sensor.

\section{Detection of biomolecules under UV light}

Several researchers in the past focused on sensing creatinine along with other biomolecules such as glucose, lactose, and urea. In Figure 4, we screened all these biomolecules using the same experimental procedure described earlier. The green color under ultraviolet (UV) light (365 nm excitation) or in normal daylight was not observed. This result suggested that the current method exclusively detects creatinine in blood samples.

\section{Concentration of creatinine in blood sample}

A series of experiments was done using the same test with PLGA FPPS and DCFH-DA, but without creatinine. Fluorescence peak at $530 \mathrm{~nm}$ was not observed, as shown in Figure 5. However, when $50 \mu \mathrm{m}$ of creatinine was added to this FPPS mixture, a peak at $530 \mathrm{~nm}$ was observed.

The creatinine level in diabetic patients exceeded the normal range. This would be expected because diabetic patients typically suffer from renal dysfunction. In Figure 6, the creatinine levels in blood from healthy individuals were compared with blood from diabetic patients. The blood from diabetic patients showed greater fluorescence intensity at $530 \mathrm{~nm}$. Figure 7 shows that as the concentration of creatinine increased, the fluorescence intensity at $530 \mathrm{~nm}$ also increased. The lower limit for detecting creatinine in blood is $5 \mu \mathrm{M}$. We took five samples of blood

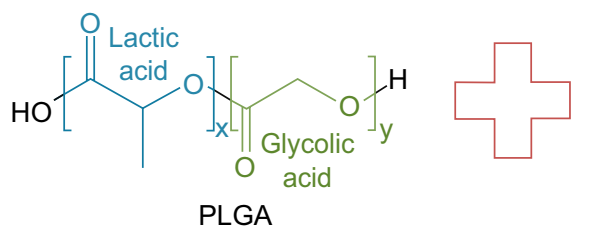

PLGA<smiles>[R]N1C=C[N+]([R])C1</smiles>

Ionic liquid

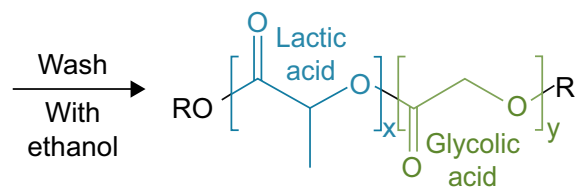

PLGA-ionic liquid based scaffold

Figure 2 This equation shows that when PLGA mixed with ionic liquid (BMIM chloride) in the presence of dichloromethane, PLGA slurry is formed.

Note: After washing with ethanol, it confirmed ester linkage with pore.

Abbreviations: BMIM, I-butyl-3-methylimidazolium; PLGA, poly-lactic-co-glycolic acid. 


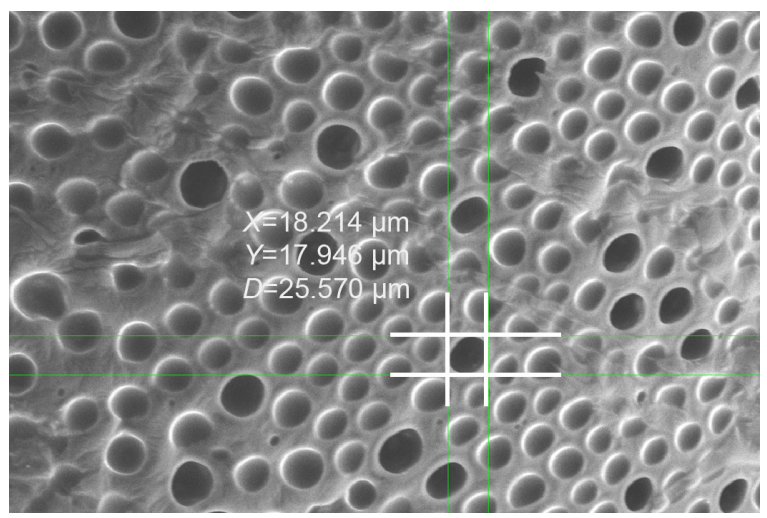

Figure 3 The average size of the pore.

Note: It was $18.214 \mu \mathrm{m}$ on the $X$-axis, $17.946 \mu \mathrm{m}$ on the $Y$-axis, and the diameter of the pore was $25.570 \mu \mathrm{m}$.

from healthy individuals, five samples from patients with Alzheimer's, and five samples from diabetic patients, and checked creatinine levels. All blood samples contained creatinine and produced a green color under UV visible light at $365 \mathrm{~nm}$ and in normal white light, as shown in Figure 8. Arvanitakis et $\mathrm{al}^{26}$ showed that creatinine has been significantly associated with Alzheimer's disease. A series of experiments proved that Alzheimer's disease was closely associated with Plasma and their result showed that Alzheimer's can be detected from Plasma. ${ }^{28-31}$ Another recent study by Yoshida et $\mathrm{al}^{27}$ described that there was a slow increase of creatinine level in case of Alzheimer's disease as compared with normal blood. Figure 9 shows that creatinine levels in patients with Alzheimer's and healthy individuals were only slightly different, whereas in diabetic patients, this difference was extremely high $(P<0.05)$. All experiments were done in triplicate. In Figure 10, a detailed

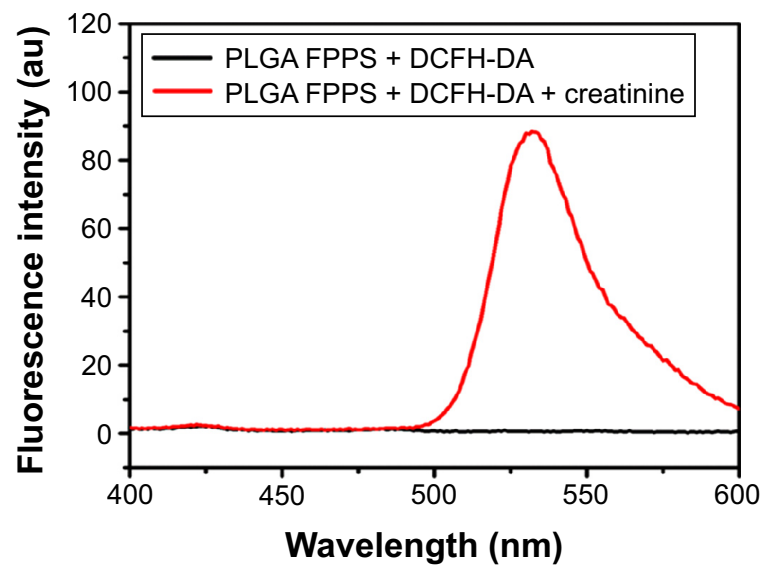

Figure 5 FPPS with DCFH-DA showed no fluorescence intensity.

Note: Addition of $50 \mu \mathrm{M}$ of creatinine resulted in fluorescence intensity at $530 \mathrm{~nm}$.

Abbreviations: au, absorption unit; DCFH-DA, 2',7'-dichlorofluorescein diacetate; FPPS, functional porous polymer structure; PLGA, poly-lactic-co-glycolic acid.

description about creatinine sensing is mentioned. In the first step, FPPS was prepared, as mentioned in "Preparation of FPPS" section. FPPS ( $5 \mathrm{mg}$ ), creatinine, and DCFH-DA were added to a $1.5 \mathrm{~mL}$ tube. Ester containing pore converted DCFH-DA to DCFH and simultaneously creatinine on hydrolysis produced $\mathrm{OH}^{-}$. This $\mathrm{OH}^{-}$helped to produce $\mathrm{DCF}^{+}$from $\mathrm{DCFH}$. As the concentration of $\mathrm{DCF}^{+}$increased, it produced more green color under UV light at $365 \mathrm{~nm}$ excitation. This is the basic mechanism, and is mentioned in Figure 10.

\section{Conclusion}

FPPS-based sensor for determining creatinine concentration in human plasma was developed. This method is similar to

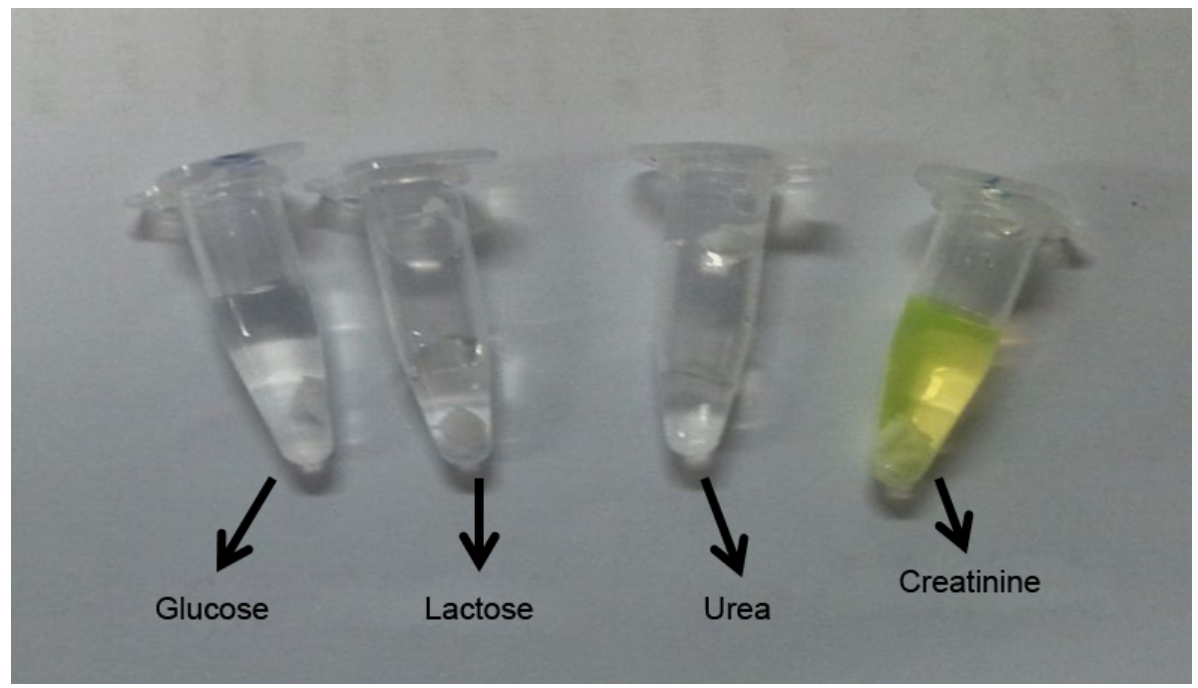

Figure 4 FPPS and DCFH-DA were used to screen different biomolecules such as glucose, lactose, and urea along with creatinine.

Note: Only creatinine showed green fluorescence under UV-visible light $(365 \mathrm{~nm})$ and green color in normal white light.

Abbreviations: DCFH-DA, 2',7'-dichlorofluorescein diacetate; FPPS, functional porous polymer structure; UV, ultraviolet. 


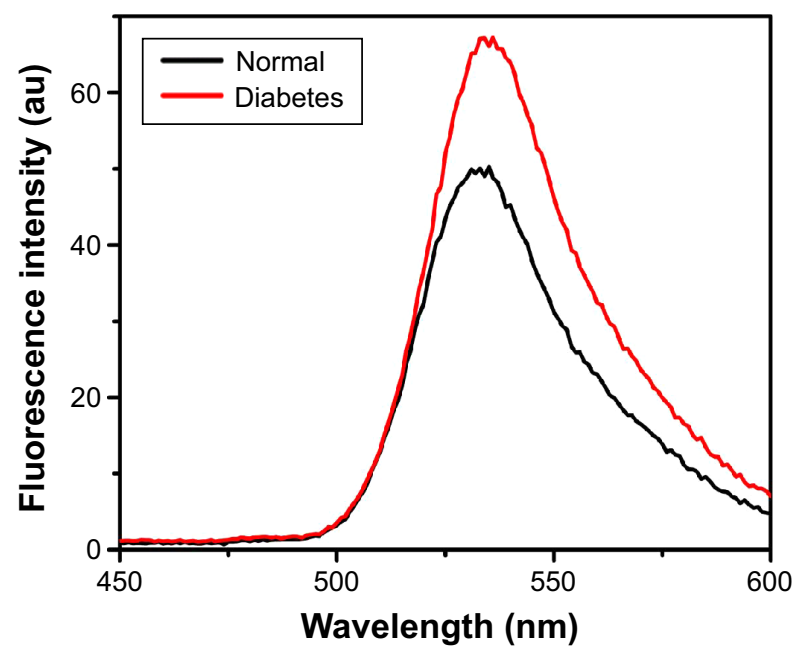

Figure 6 The creatinine concentration was higher in blood samples from diabetic patients and showed more fluorescence intensity compared with blood from normal individuals.

Abbreviation: au, absorption unit.

other conventional clinical methods that are presently used. Current method can detect only creatinine in blood sample. In the near future, more focus on improving the sensor by increasing the fluorescence intensity should be carried out. This will allow the diabetes patient to use this sensor and check their creatinine level. This creatinine sensor can be especially useful for patients with renal disease or patients

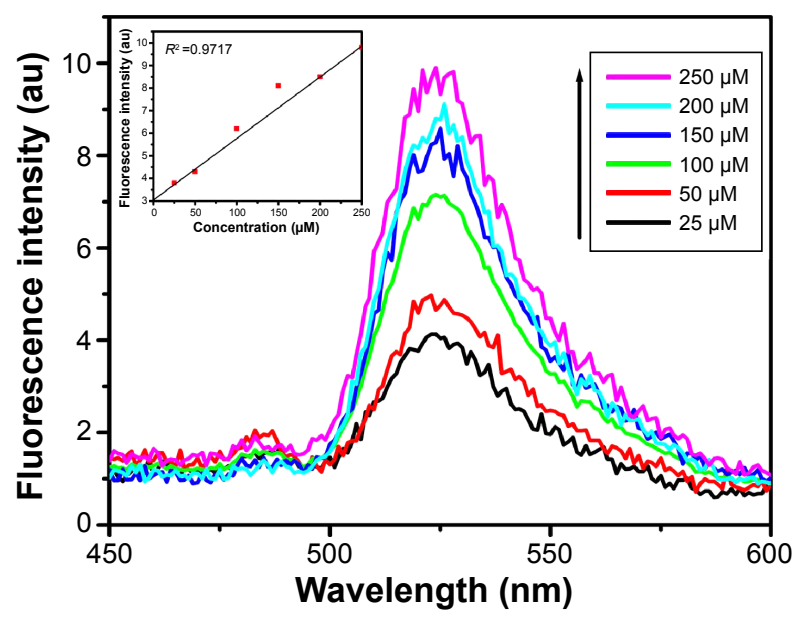

Figure 7 As the concentration of creatinine increased, the fluorescence intensity (at $530 \mathrm{~nm}$ ) of the samples also increased.

Note: A sharp increase in the emission peak was observed as the concentration of creatinine increased.

Abbreviation: au, absorption unit.

who have undergone kidney transplantations, as they can use it for home monitoring. This sensor is selective for creatinine only, and other biomolecules are not measured. With the help of nanoparticles, this method can be further improved by altering the morphology and size of the particles, external area of the pore, and adsorption properties and by increasing the transfer of electrons.
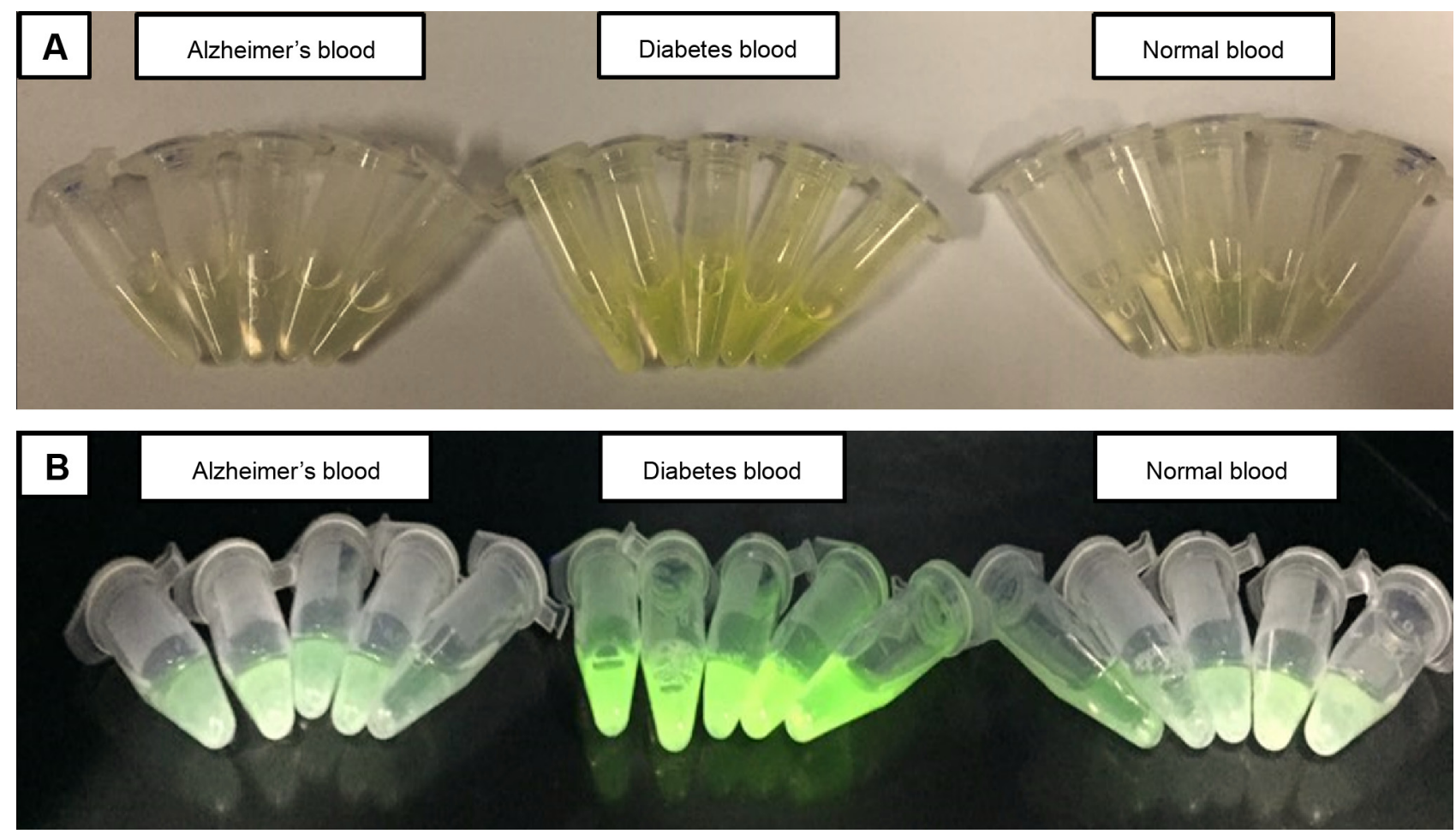

Figure 8 Creatinine levels in five blood samples from healthy individuals, five from patients with Alzheimer's, and five from diabetic patients.

Notes: (A) Sample contained creatinine in normal eye with Alzheimer's blood, Diabetes blood and Normal blood. (B) Sample contained creatinine under UV light at $365 \mathrm{~nm}$ with Alzheimer's blood, Diabetes blood and Normal blood. They also produced green color in normal white light. The color intensity in the blood samples from diabetic patients was higher compared to other blood samples. 


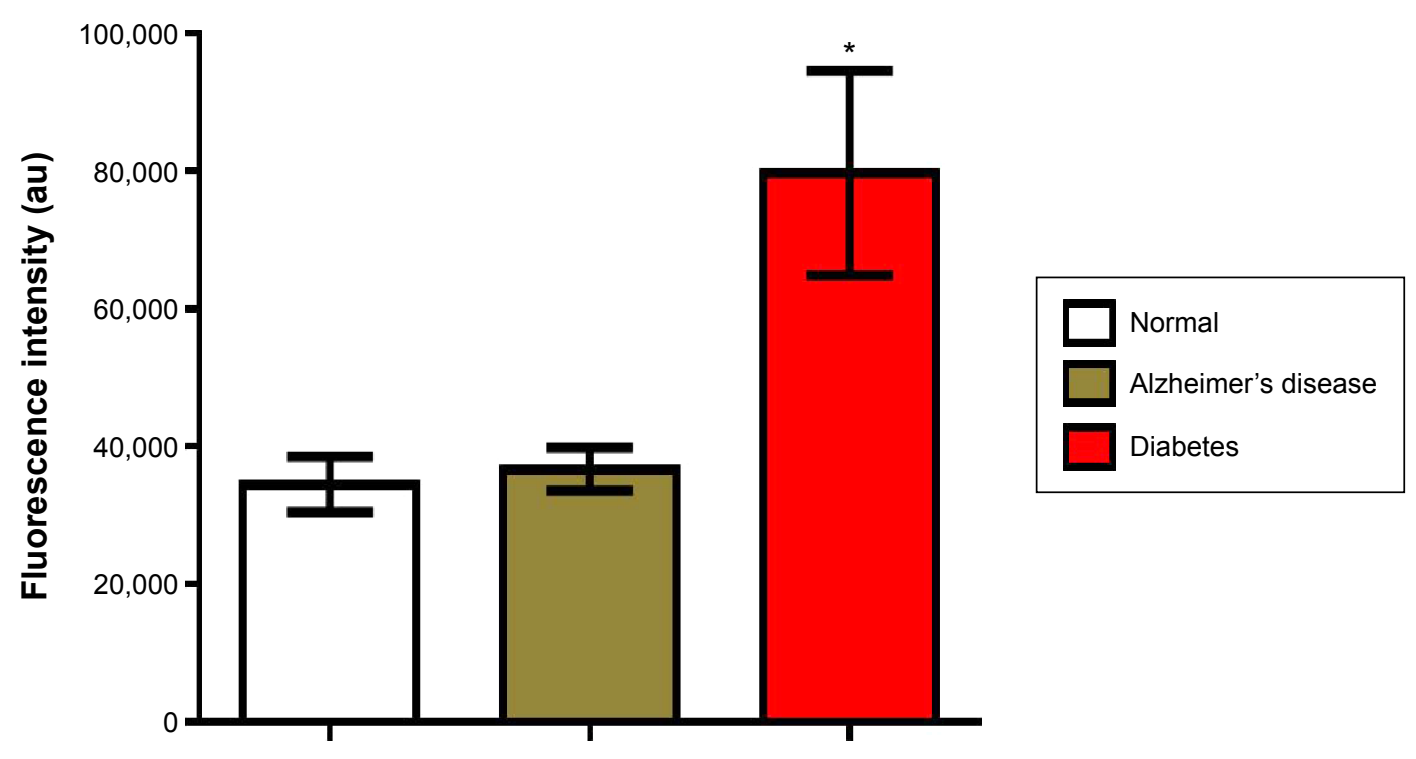

Figure 9 The optical density of blood sample.

Notes: Creatinine levels in five blood samples from healthy individuals, five from patients with Alzheimer's, and five from diabetic patients. $* P<0.00 \mathrm{I}$ by one-way ANOVA followed by Tukey's test.

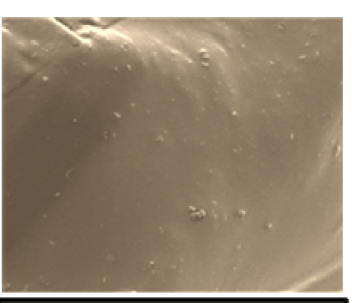

PLGA with dichloromethane

Addition of
BMIM chloride

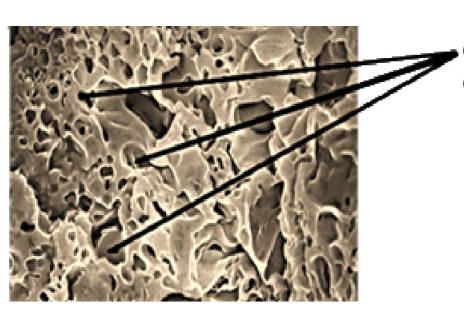

Pore contained ester linkage which converted DCFHDA to DCFH

Addition of FPPS into diluted blood sample

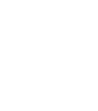

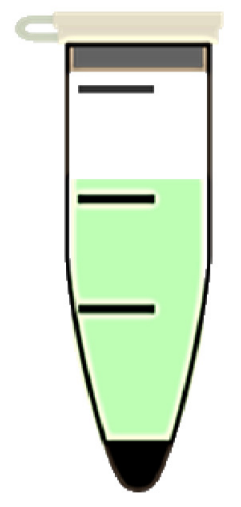

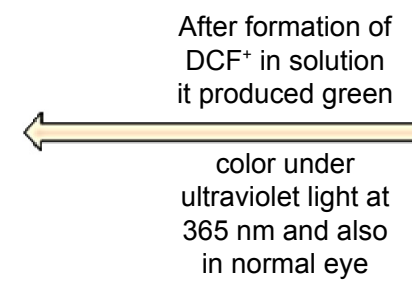




\section{Acknowledgment}

This work was supported by the grants of National Research Foundation of Korea (NRF), funded by the South Korean government (MEST) (2012R1A2A2A03046819) and (2013R1A1A2005329). The authors wish to thank Prof. Kwnagwon Kim from Gachon University Gil Hospital and SangYun from Seoul National University Bundang Hospital for plasma samples as gifts.

\section{Disclosure}

The authors report no conflicts of interest in this work.

\section{References}

1. Kazmlerczak SC, Lente FV, Hodges ED. Diagnostic and prognostic utility of phospholipase: a activity in patients with acute pancreatitis: comparison with amylase and lipase. Clin Chem. 1991;37:356-360.

2. Tietz NW. Textbook of Clinical Chemistry. 1st ed. Philadelphia, PA: WB Saunders; 1986:1810-1857.

3. Schenk PW, Cransberg K, Wolff ED, De Rijke YB. Point-of-care creatinine testing in children at risk for sudden deterioration of renal function. Clin Chem Lab Med. 2007;45:1536-1541.

4. Udy A, O’Donoghue S, D'Intini V, Healy H, Lipman J. Point of care measurement of plasma creatinine in critically ill patients with acute kidney injury. Anaesthesia. 2009;64:403-407.

5. Jaffe MZ. About generates the precipitation which picric acid in normal urine and a new reaction of creatinine. Z Physiol Chem. 1886;10: 391-400. German.

6. Weber JA, Van Zenten AP. Interferences in current methods for measurements of creatinine. Clin Chem. 1991;37:695-700.

7. Lo SC, Tsai KS. Glucose interference in Jaffé creatinine method: effect of calcium from peritoneal dialysate. Clin Chem. 1994;40:2326-2327.

8. Kochansky CJ, Strein TG. Determination of uremic toxins in biofluids: creatinine, creatine, uric acid and xanthenes. J Chromatogr B. 2000; 747:217-227.

9. Kihara K, Yasukawa E. Determination of creatinine with a sensor based on immobilized glutamate dehydrogenase and creatinine deiminase. Anal Chim Acta. 1986;183:75-80.

10. Battilotti M, Colapicchioni C, Giannini I, et al. Characterization of biosensors based on membranes containing a conducting polymer. Anal Chim Acta. 1989;221:157-161.

11. Jurkiewicz M, Alegret S, Fabregas E. Comparison of flow injection analytical biosystems based on open-tube and packed-bed enzyme reactors. Anal Chim Acta. 1998;370:47-58.

12. Jurkiewicz M, Alegret S, Almirall J, Garcia M, Fabregas E. Development of a biparametric bioanalyser for creatinine and urea. Validation of the determination of biochemical parameters associated with hemodialysis. Analyst. 1998;123:1321-1327.
13. Osaka T, Komaba S, Amano A, Fujino Y, Mori H. Electrochemical molecular sieving of the polyion complex film for designing highly sensitive biosensor for creatinine. Sens Actuators B. 2000;65: $58-63$.

14. Kubo I, Karube I. Immobilization of creatinine deiminase on a substituted poly (methylglutamate) membrane and its use in a creatinine sensor. Anal Chim Acta. 1986;187:31-37.

15. Nguyen VK, Wolff CM, Seris JL, Schwing JP. Immobilized enzyme electrode for creatinine determination in serum. Anal Chem. 1991;63: 611-614.

16. Yamato H, Ohwa M, Wernet WA. Polypyrrole/three-enzyme electrode for creatinine detection. Anal Chem. 1995;67:2776-2780.

17. Madaras MB, Buck RP. Miniaturized biosensors employing electropolymerized permselective films and their use for creatinine assays in human serum. Anal Chem. 1996;68:3832-3839.

18. Schneider J, Grundig B, Renneberg R, et al. Hydrogel matrix for three enzyme entrapment in creatine/creatinine amperometric biosensing. Anal Chim Acta. 1996;325:161-167.

19. Khan GF, Wernet W. A highly sensitive amperometric creatinine sensor. Anal Chim Acta. 1997;351:151-158.

20. Madaras MB, Popescu IC, Ufer S, Buck RP. Microfabricated amperometric creatine and creatinine biosensors. Anal Chim Acta. 1996;319: 335-345.

21. Shih YT, Huang HJ. A creatinine deiminase modified polyaniline electrode for creatinine analysis. Anal Chim Acta. 1999;392:143-150.

22. Welton T. Room-temperature ionic liquids. Solvent for synthesis and catalysis. Chem Rev. 1999;99:2071-2083.

23. Sheldon R. Catalytic reactions in ionic liquids. Chem Commun. 2001;2: 399-407.

24. Song CE. Enantioselective chemo- and bio-catalysis in ionic liquids Chem Commun. 2004;9:1033-1043.

25. Gericke M, Fardim P, Heinze T. Ionic liquids - promising but challenging solvents for homogeneous derivatization of cellulose. Molecules. 2012;17:7458-7502.

26. Arvanitakis Z, Lucas JA, Younkin LH, Younkin SG, Graff-Radford NR. Serum creatinine levels correlate with plasma amyloid Beta protein. Alzheimer Dis Assoc Disord. 2002;16:187-190.

27. Yoshida M, Higashi K, Kuni K, et al. Distinguishing mild cognitive impairment from Alzheimer's disease with acrolein metabolites and creatinine in urine. Clin Chim Acta. 2015;441:115-121.

28. Toledo JB, Shaw LM, Trojanowski JQ. Plasma amyloid beta measurements - a desired but elusive Alzheimer's disease biomarker. Alzheimers Res Ther. 2013;5:8.

29. Irizarry MC, Gurol ME, Raju S, et al. Association of homocysteine with plasma amyloid beta protein in aging and neurodegenerative disease Neurology. 2005;65:1402-1408.

30. Luchsinger JA, Tang MX, Miller J, Green R, Mehta PD, Mayeux R. Relation of plasma homocysteine to plasma amyloid beta levels Neurochem Res. 2007;32:775-781.

31. Rajagopalan P, Refsum H, Hua X, et al. Mapping creatinine- and cystatin C-related white matter brain deficits in the elderly. Neurobiol Aging. 2013; 34:1221-1230.
International Journal of Nanomedicine

\section{Publish your work in this journal}

The International Journal of Nanomedicine is an international, peerreviewed journal focusing on the application of nanotechnology in diagnostics, therapeutics, and drug delivery systems throughou the biomedical field. This journal is indexed on PubMed Central, MedLine, CAS, SciSearch ${ }^{\circledR}$, Current Contents ${ }^{\circledR} /$ Clinical Medicine,

\section{Dovepress}

Journal Citation Reports/Science Edition, EMBase, Scopus and the Elsevier Bibliographic databases. The manuscript management system is completely online and includes a very quick and fair peer-review system, which is all easy to use. Visit http://www.dovepress.com/ testimonials.php to read real quotes from published authors. 